\title{
Brain Tumor and Pregnancy
}

\author{
Akhvlediani KN ${ }^{1 *}$, Logutova LS ${ }^{1}$, Travkina AA ${ }^{1}$, Lubnin A Yu² and Melnikov AP ${ }^{1}$ \\ ${ }^{1}$ Department of the Ministry of Health and Social Development GBUZ MO, Moscow Regional Research Institute of Obstetrics and Gynecology, Russia \\ ${ }^{2}$ Department of Intensive Care Unit, FSAI National Scientific and Practical Center of Neurosurgery by academician NN Burdenko MZ RF, Russia
}

Submission: December 18, 2017; Published: January 08, 2018

*Corresponding author: Akhvlediani KN, Department of the Ministry of Health and Social Development GBUZ MO, Moscow Regional Research Institute of Obstetrics and Gynecology, Russia, Tel: 84956230097; Email: akhketi@mail.ru

\begin{abstract}
Brain tumors (BT) are not frequent but one of the most difficult clinical situations which oblige prescribes strictly individualized treatment. The experience of searching the pregnancy. And delivery of patients with brain tumors is presented. There were 45 patients with BT in all patients. The structure of BT in pregnant patients is cited. The mode of delivery is predominantly the vaginal route, a number of operative vaginal delivery is also present.
\end{abstract}

Keywords: Pregnancy; Brain tumor; Computer tomography; Cesarean section; Vacuum-extraction of the fetus

\section{Introduction}

Brain tumors (BT) are not frequent but one of the most difficult clinical situations which oblige prescribes strictly individualized treatment [1]. There are no real data of frequency of such pathology in pregnant patients, only extrapolation. Clinical signs of BT may be noted during the course of pregnancy because intracranial tumors are found in $75 \%$ of cases in the reproductive period [2]. The maternal mortality among women with BT is extremely high and reaches $24,3 \%[3,4]$. The course and outcome of BT during pregnancy are usually unfavorable. Pregnancy interruption causes only temporary improvement.

Aim: to improve maternal and perinatal out comes in pregnant patients with BT by optimization of the pregnancy course, labor and puerperal period with help of early diagnosing, timely specialized effective treatment.

\section{Material and Methods of Investigation}

45 pregnant women aged 21-30 were under our supervision. They were divided in 2 groups: the first consisted 11 patients with BT found in the present pregnancy: in one case there was a neurinoma of the acoustic nerve, in two - astrocytoma of Grade I and II, in two - glioma of Grade II and III, and in four - glioblastomas Grade III- IV, there was 1 case with oligodendroglioma. Irradiation has been taken place in pregnant patients with the glioma of the brains stem (15 courses). The BT has been diagnosed during the second trimester of pregnancy in 16-32 weeks of pregnancy. The second group included 34 pregnant patients with BT of different localizations after neurosurgical treatment. The histology showed astrocytoma
Grade I and II in 30 cases and meningioma in 2 cases, 1 case of medulloblastoma and 1 case of neurocytoma the interval from operation up to the state of pregnancy is 1-2 years. Every patient endured skull trepanation, tumor eradiation, in 5 cases chimioand ray treatments were accomplished.

All patients had computerized tomography to define the localization and spreading of the neoplasm in conditions of the ray defense of the fetus and standard clinical and laboratory methods of examination. Also magneto-resonance tomography and electroencephalography to find local disturbances of brains biopotentials and /or evaluation of the cerebral disturbances on the whole have been fulfilled. All patients were consulted by neuro-ophtalmolog, anaesthesiolog, neurology. Dynamic ultrasound examinations of the fetus, the study of the hormonal status of the feto-placental complex were carried out.

\section{Obtained Results and Discussion}

The patients of the first group had anaemia in 3 cases and faeto-placental insufficiency in 2 cases. The first clinical signs of the tumor were presented as common cerebral symptoms: nausea, vomiting, visual disturbances and they were estimated as pregnancy complications. But later local symptoms joined ${ }^{\wedge}$ epileptic attack, hypertension, Hydrocephalic syndrome, diminution of hearing. The treatment included antiepileptic drugs, corticosteroids, therapy of the feto-placental insuffiency. There was regress of common cerebral and local symptoms in 6 cases and the pregnancy was prolonged up to 37 weeks/four patients has simultaneous operation at 32-34 weeks of gestation 
due to progress of the neurologist symptoms: cesarean section and neoplasms withdrawal.

According to literature the abdominal delivery presents up to $75 \%$ of cases [5]. Our patient with acoustic nerve's neurinoma has been delivered at 32 weeks of gestation. Then at the 7 th postoperative day she has been transported the neurosurgical department where the tumor has been eradicated. The babies from patients of the first group were born in satisfactory condition with Apgar score 6 and 8 and in 5 days the condition has been estimated as satisfactory. In 1 case in puerperium according to the tumor histology there was combined radiation and chemotherapy (8 courses of Temozolomide).

Among the patients of the second group the course of pregnancy was complicated by threatened abortion in 5 cases, feto-placental insuffiency in 2 cases, anaemia in 3 cases. Symptomatic epileptic attacks have been in 3 cases despite antiepileptic drug's treatment. 12 patients were delivered by cesarean section, 18 patients by spontaneous vaginal delivery: 3 cases with vacuum-extraction and 1 with obstetric forceps. 29 babies have been born in good condition with the Apgar score 8 and 9, 4 babies had Apgar score 7/8 on the 2nd puerperal day their condition was satisfactory, 1 baby delivered with the score 7 and 8 according to Apgar scale had intrauterine pneumonia and was transported to the department of the pathology of newborn. Four premature babies had 1600-2400g of weight, score by Apgar scale 6 and 8, all of them have been transported to the department of the pathology of newborns. As a catamnesis the inspiration for 3 years has been accomplished: neither worsening of the patient's condition nor the progress of neurologist symptoms. There was no maternal lethality. 4 patients had died in 1, 5-2 years after delivery (glioblastomas of Grade III-IV).

\section{Conclusion}

The optimal strategy of delivery of pregnant patients with BT is pregnancy prolongation to term and simultaneous operation of cesarean section and neurosurgical tumor removal with combined treatment in puerperal period according to data of the histological examination. The progressing of common cerebral symptoms and local symptoms, hypertension hydrocephalic syndrome or progressive vision disturbances forces neurosurgical operation to be accomplished with possible prolongation of pregnancy and forthcoming operative delivery.

\section{References}

1. Greenberg MS (2010) Handbook of Neurosurgery. In: Greenberg MS (ed.), Tumors (ch. 21), ( $7^{\text {th }}$ Edn), Thieme, Berlin, Germany, pp. 582-769.

2. Amant F, Van Calsteren K, Halaska MJ, Gziri MM, Hui W,et al. (2012) Long-term cognitive and cardiac outcomes after prenatal exposure to chemotherapy in children aged 18 months or older: an observational study. Lancet Oncol 13(3): 256-264.

3. Bondy ML, Scheurer ME, Malmer B, Barnholtz-Sloan JS, Davis FG, et al. (2008) Brain tumor epidemiology: consensus from the Brain Tumor Epidemiology Consortium. Cancer 113(7 Suppl): 1953-1968.

4. Yust-Katz S, de Groot JF, Liu D, Wu J, Yuan Y, et al. (2014) Pregnancy and glial brain tumors. Neuro Oncol 16(9): 1289-1294.

5. Bonfield CM, Eng JA (2012) Pregnancy and brain tumors. Neurol Clin 30: 937-946.

\section{Your next submission with Juniper Publishers} will reach you the below assets

- Quality Editorial service

- Swift Peer Review

- Reprints availability

- E-prints Service

- Manuscript Podcast for convenient understanding

- Global attainment for your research

- Manuscript accessibility in different formats ( Pdf, E-pub, Full Text, Audio)

- Unceasing customer service

Track the below URL for one-step submission https://juniperpublishers.com/online-submission.php 